\title{
Cotas e mulheres nas eleições legislativas de 2014
}

\author{
Vitor de Moraes Peixoto 1 \\ Nelson Luis Motta Goulart ${ }^{2}$ \\ Gabriel Tisse da Silva ${ }^{3}$
}

\section{Resumo}

Este artigo explora as consequências das inovações institucionais introduzidas na legislação eleitoral brasileira com as políticas de discriminação positivas, como as cotas para as mulheres nas listas partidárias. Descreve a trajetória da legislação pós-1988 e analisa o aumento significativo da participação feminina nas eleições e o baixo sucesso eleitoral tanto para a Câmara dos Deputados quanto para as Assembleias Legislativas Estaduais. Apresenta-se, por fim, um modelo econométrico para mensurar o impacto da variável gênero e demais atributos individuais dos candidatos nas eleições de 2014.

Palavras-chave: Eleições legislativas; representação; cotas de gênero; financiamento de campanhas.

\section{Introdução}

0 acesso das mulheres à esfera pública, de modo geral, é dificultado por um duplo complicador sustentado na prerrogativa da não cidadania das mulheres, caracterização que as enquadra como sujeitos passivos, vinculados à esfera privada e desprovidos de requisitos para interferir na esfera pública. A representação das mulheres, desse modo, também está condicionada por esse fator de exclusão do público. Esse princípio, inerente de uma exclusão da cidadania das mulheres, deriva na negativa da condição de sujeito ativo, de cidadãs, às mulheres (ARAÚJO, 2012b, p.154).

0 Movimento Feminista pode ser diretamente ligado às conquistas sociais e políticas das mulheres. As críticas, a mobilização e as lutas produziram ganhos para as mulheres, entre eles, talvez o principal, o direito de votar e serem votadas. As sufragistas americanas

\footnotetext{
${ }^{1}$ Doutor em Ciência Política pelo IUPERJ e Professor Associado da Universidade Estadual do Norte Fluminense (UENF). E-mail: moraespeixoto@gmail.com.

2 Mestrando em Sociologia Política na da Universidade Estadual do Norte Fluminense. E-mail: nl.goulart@gmail.com.

${ }^{3}$ Graduando em Ciências Sociais na da Universidade Estadual do Norte Fluminense (UENF). E-mail: gabrieltissedasilva@gmail.com.
} 
do século XIX acreditavam que a conquista do voto representaria "o milênio para as mulheres". 0 baixo número de eleitas após essa conquista, no entanto, demonstrou a necessidade de se identificar mecanismos de exclusão mais profundos (BIROLI; MIGUEL, 2014, p.8).

A luta pelo voto também foi a manifestação inicial da primeira onda do feminismo no Brasil (PINT0, 2012, p.270). A Fundação Brasileira pelo Progresso Feminino, que teve Bertha Lutz como uma de suas fundadoras, fez campanha pública pela participação eleitoral das mulheres. 0 direito de votar, contudo, só seria conquistado na década de 1930, com a promulgação do Novo Código Eleitoral Brasileiro durante o período constitucionalista do Getulismo. Não seria arriscado afirmar que houve a criação de uma janela de oportunidade ótima para a inovação institucional representada pela incorporação das mulheres à dimensão da participação político-eleitoral. Por um lado, havia um momento político internacional que exercia uma forte pressão externa, por outro, uma necessidade do governo getulista de ampliar apoio social combinadaa uma mobilização popular.

A conquista do voto feminino em todo o Brasilse deu em 1932, a partir do Código Eleitoral, e mais tarde recepcionado pela Constituição de 1934. 0 Código Eleitoral e também a Constituição, mesmo sendo mais inclusivos à participação das mulheres e tendo a obrigatoriedade do voto para os sujeitos aptos a ele, não fizeram efetivamente com que grande parte da população feminina votasse. 0 contingente de adultos cadastrados foi de apenas 3,9\% de uma população absoluta de 36.974 milhões de habitantes (NICOLAU, 2002, p.38). Isto porque os analfabetos estavam alijados da participação política desde a reforma eleitoral em 1882, que representou um grande retrocesso nas conquistas da cidadania política (CARVALHO, 2001).

Após um longo processo de criação de instituições democráticas no período entre 1946-64, que se notabilizou pela intensa urbanização e uma incipiente industrialização nacional, a participação das mulheres nas esferas de poder permanecia pouco expressiva (SOARES, 2001). Nos anos 70, o movimento feminista demonstrou que a ausência das mulheres do poder era um sinal de um sintoma de exclusão de base estrutural, e não apenas o expoente de uma menor inclinação das mulheres para a carreira política (MIGUEL; QUEIROZ, 2006, p.363). 0 intenso crescimento das cidades, a ampliação do setor de serviços e a entrada das mulheres no mercado de trabalho foram importantes fatores que explicam o crescimento do movimento feminista, principalmente no que diz respeito à participação política.

As décadas de 60 e 70, porém, foram períodos conturbados para o desenvolvimento das lutas e reivindicações libertárias no Brasil, em 
decorrência do Regime Militar em vigor. 0 ambiente de repressão e forte controle, em que "as eleições foram suspensas ou restringidas para todos os cargos eleitos pelo sistema majoritário" (NICOLAU, 2002, p. 55), dificultou em grande parte o desenvolvimento e aquisição de direitos ligados a causas vinculadas a liberdades individuais, ao contrário do que acontecia na Europa e nos Estados Unidos.

Os movimentos sociais, em geral, se organizaram para garantir sua participação em ações decisórias, haja vista que, ainda nos dias atuais, o perfil dos representantes políticos em sua maioria é "mais masculino, muito mais rico, muito mais instruído e muito mais branco" (MIGUEL; QUEIROZ, 2006, p. 364). O movimento feminista, também inserido na busca pela representação, passou a apoiar-se em seu novo slogan, cunhado nos anos 1960: "o pessoal é político" (ARAÚJO, 2012a, p. 246).

Na virada da década de 70 para 80 , porém, o feminismo brasileiro entrou em uma fase de grande efervescência de sua luta pelos direitos das mulheres com as campanhas da redemocratização (PINTO, 2012, p.273). Os anos 80 representaram um marco na história política brasileira por ter sido em 1985 a primeira vez na história do país republicano que analfabetos puderam votar, mesmo que não pudessem ser eleitos (NICOLAU, 2002, p.61). Nesse período há uma aproximação entre os grupos de mulheres, que acabaram, muitas vezes, se organizando próximos a movimentos populares. 0 encontro produziu novas percepções ao movimento, que tinha como seu germe a classe média intelectualizada brasileira (PINTO, 2012, p.273).

Após um longo processo de incorporação das mulheres na dimensão política da cidadania, o déficit nas arenas de poder ainda é grande. Após mais de 80 anos da eleição da primeira mulher para Câmara dos Deputados, ainda existem relativamente poucas mulheres participando das eleições e um número bem menor delas sendo eleitas.

Este artigo explora as consequências das inovações institucionais introduzidas na legislação eleitoral brasileira com as políticas de discriminação positivas, como as cotas para as mulheres nas listas partidárias. Descreve a trajetória da legislação pós-1988 e analisa o aumento significativo da participação feminina nas eleições e o baixo sucesso eleitoral tanto para a Câmara dos Deputados quanto para as Assembleias Legislativas estaduais. Apresenta-se, por fim, um modelo econométrico para mensurar o impacto da variável gênero e demais atributos individuais dos candidatos nas eleições de 2014, verificandose que o controle pelos gastos retira o poder explicativo de ser mulher. 


\section{As cotas por sexo e desempenho nas eleições legislativas}

Norris, Inglehart e Welzel (2004) apontam que existem características que impactam diretamente nas chances das mulheres atingirem a representação, concretizada na eleição. As três características principais apontadas são: o contexto institucional, as ações afirmativas nas estratégias de composição das listas partidáriase os recursos que homens e mulheres trazem para o seguimento de suas carreiras políticas.

Os mecanismos de cotas de gênero surgiram como soluções institucionais utilizadas com o intuito de mitigar a disparidade entre o contingente de mulheres e homens eleitos, para minimizar a situação de sub-representação política das mulheres (KROOK, 2004). As cotas eleitorais para mulheres foram implementadas nas democracias modernas gradualmente desde o final do século XX, o que já soma mais de cem países. Essas medidas começaram a ser implementadas no último século por várias democracias, o que caracteriza esse fenômeno como recente e global. Embora a literatura majoritariamente aponte que as cotas se tratam de fenômenos domésticos relacionados à mobilização de grupos de mulheres, cálculos de elites políticas e também conexões entre imperativos de normas políticas (KROOK, 2004).

Krook (2004) apontou a existência de três categoriais principais de cotas de gênero, cujo objetivo é o aumento da representação das mulheres: reserved seat, political party quotas e nationa llegislative quotas. As que são reserved seat, estipulam um determinado número de cadeiras, nos parlamentos. As party quotas, por sua vez, tratam-se de políticas intrapartidárias com o objetivo de aumentar a proporção de mulheres como candidatas e eleitas. As legislative quotas, por fim, impõem aos partidos a obrigatoriedade, ou recomendação, de nomear certa proporção de mulheres nas listas eleitorais.

Today, nearly all countries in the world have pledged to promote gender-balanced decision-making. More than eighty have seen the adoption of quotas for the selection of female candidates, and more than twenty more have initiated quota debates over the last ten years (KROOK, 2004, p. 2).

A aparente alta adesão e implementação dessas medidas, contudo, é um processo recente e implementado em sua maioria na década de 1990 (KROOK, 2004). A data é coincidente com a UN's Fourth World Conference on Women, realizada em Pequim em 1995, à qual é creditada grande influência no avanço dos estudos de gênero, incluindo o da sub-representação política, e difusão dessas medidas. 
No Brasil, uma série de inovações institucionais ocorreu na legislação eleitoral no intuito de corrigir a sub-representação das mulheres na política após 1990. As primeiras políticas de discriminação positiva foram introduzidas em meados da década de 90. "A primeira proposta de cotas foi apresentada em 1995 na eleição para as Câmaras Municipais" (ARAÚJ0, 2001, p.9), quando foram estabelecidas as cotas pela Lei 9.100/95. Já nas eleições de 1996 constatou-se "que os percentuais de candidaturas... se aproximavam da cota mínima estabelecida, naquela eleição estipulada em 20\%...” (ARAÚJ0, 2001, p.10). 0 objetivo das cotas estava primeiramente orientado em dois pontos:

primeiro, mais concreto, que seria o de ampliar a presença de mulheres na representação política como candidatas, mas sobretudo como eleitas; e um segundo, definido como mais simbólico visando alterar a cultura política marcada por percepções de gênero que naturaliza as desigualdades... (ARAÚJO, 2001, p.10)

A legislação, entretanto, era considerada uma norma programática pelo Tribunal Superior Eleitoral (TSE) e permaneceu sem consequências efetivas até as modificações realizadas pela Lei 9.504/97, quando se estabeleceu o mecanismo de reserva de $30 \%$ de vagas para um dos sexos. Na prática, os partidos e coligações estavam proibidos de ocupar todas as vagas disponíveis somente com homens, ainda que não houvesse uma única mulher na nominata.

Nas eleições proporcionais de 2006, por exemplo, concorreram apenas 2.355 mulheres $(13,8 \%$ do total de candidatos para ambos os cargos), sendo 1.736 para o cargo de Deputada Estadual (14,3\% deste cargo), e 626 para Deputada Federal (12,6\% do total de candidatos para este cargo). Mesmo possuindo um sistema de cotas, que reserva às mulheres $30 \%$ das vagas nas listas partidárias, o percentual de mulheres para ambos os cargos ainda é muito baixo se comparado ao percentual de homens.

As cotas, nas eleições de 2006, ainda eram relativas ao total de candidatos possíveis para cada cargo por partido ou coligação; e não ao número efetivo de candidatos registrados. Dito de outra forma, existiu a reserva de vagas, mas não a obrigatoriedade de registros de candidaturas femininas. Como cada partido ou coligação pode registrar um número de candidatos de até $150 \%$ das vagas em disputa, muitas dessas reservadas simplesmente não são preenchidas, exatamente as que deveriam ser destinadas às mulheres. 0 caso da Assembleia Legislativa de Santa Catarina pode servir de exemplo: são ao todo 40 vagas em disputa. Cada partido ou coligação pode, então, registrar até 
60 candidatos. Porém, deverá reservar o mínimo 30\% (18 vagas) e o máximo de $70 \%$ (42 vagas) para cada sexo. Na prática, isso significa que o partido ou coligação não está obrigado a registrar o mínimo de 18 mulheres (poderia registrar nenhuma), mas não poderá registrar mais do que 42 homens.

Somente em 2009 o preenchimento destas vagas passou a ser interpretado como obrigatório com a Lei 12.034/09, e as vagas foram finalmente ocupadas por mulheres. Todavia, o preenchimento obrigatório das vagas não impactou mecanicamente no percentual de mulheres eleitas. De outra forma, ainda que a legislação obrigue os partidos e coligações a incluírem mulheres em suas listas, outros obstáculos discriminatórios não foram retirados do sistema. Como todos os direitos da luta feminista, a inclusão na esfera política da representação parlamentar tem sido bastante lenta e gradual.

O cenário eleitoral, então, modifica-se nas eleições nacionais de 2010, já sob a vigência das cotas com obrigatoriedade de preenchimento das vagas. As mudanças na legislação eleitoral provocaram um aumento substancial no número de candidatas, como se observa na Tabela 1. No entanto, estas inovações institucionais foram ineficazes em produzir efeitos significativos no total de eleitas.

Tabela 1: Total de candidaturas por cargo e ano (2006-2010-2014)

\begin{tabular}{|c|c|c|c|c|c|c|c|}
\hline & & \multicolumn{3}{|c|}{ Deputado Federal } & \multicolumn{3}{|c|}{$\begin{array}{c}\text { Deputado } \\
\text { Estadual/Distrital }\end{array}$} \\
\hline & & $\begin{array}{c}\text { Não } \\
\text { eleitos }\end{array}$ & Eleitos & Total & $\begin{array}{c}\text { Não } \\
\text { eleitos }\end{array}$ & Eleitos & Total \\
\hline \multirow[t]{2}{*}{2006} & FEMININO & 581 & 45 & 626 & 1.612 & 124 & 1.736 \\
\hline & MASCULINO & 3.857 & 468 & 4.325 & 9.458 & 935 & 10.393 \\
\hline \multirow[t]{2}{*}{2010} & FEMININO & 889 & 45 & 934 & 2.513 & 138 & 2.651 \\
\hline & MASCULINO & 3.500 & 468 & 3.968 & 9.088 & 921 & 10.009 \\
\hline \multirow[t]{2}{*}{2014} & FEMININO & 1.674 & 51 & 1.725 & 4.332 & 120 & 4452 \\
\hline & MASCULINO & 3.702 & 462 & 4.164 & 9.910 & 939 & 10.849 \\
\hline & Total & 14.203 & 1.539 & 15.742 & 36.913 & 3.177 & 40.090 \\
\hline
\end{tabular}

Fonte: Dados calculados pelos autores com base nas informações do TSE.

Quando se compara os totais de eleitos, percebe-se que houve uma grande estabilidade entre homens e mulheres. Enquanto o número de candidaturas mulheres à Câmara dos Deputados de 2006 a 2014 quase triplicou (de 626 para 1.725 candidatas), o total de homens na disputa para o cargo de Deputado Federal diminuiu no mesmo período (de 4.325 para 4.164 ). 
O total de homens nas disputas para o cargo de Deputado Federal aumentou apenas 4,93\% de 2010 para 2014 (passou de 3.968 para 4.164 candidatos), embora o total de eleitos tenha permanecido praticamente inalterado (pequena redução de 1,28\%, ou seja, de 468 para 462 eleitos). No que concerne ao cargo de Deputado Estadual, o contingente masculino aumentou 8,39\% (de 10.009 para 10.849 candidatos), e o total de eleitos sofreu uma variação positiva de apenas 1,95\% no mesmo período (921 para 939 eleitos).

No período, a novidade foi observada no contingente de mulheres, onde se verificou um aumento significativo na oferta de candidatas, sem consequências para o número de eleitas, contudo. Apenas 45 mulheres se elegeram para a Câmara dos Deputados em 2006 (exatamente o mesmo número de eleitas em 2010), e 51 nas eleições de 2014. A presença feminina nas Assembleias Legislativas Estaduais também não foi numericamente alterada: passou de 124 em 2006 para 138 em 2010, retornando para 120 mulheres eleitas em 2014.

Os Gráficos 1 e 2 auxiliam a interpretação ao apresentar os percentuais de candidaturas de cada sexo para ambos os cargos nas três eleições em análise.É evidente como a proporção de mulheres candidatas aumenta no período, permanecendo inalterada a proporção de eleitas.

0 aumento proporcional de candidaturas foi maior para os cargos de Deputado Estadual/Distrital do que para Deputado Federal nas eleições de 2006 para 2010. Em 2006 as mulheres compunham 12,64\% do total de candidatos para Deputado Federal e 14,31\% para Deputado Estadual/Distrital; já em 2010 elas compunham 19,1\% e 20,9\% do total de candidatos para Deputado Federal e Estadual/Distrital, respectivamente.

De 2010 para 2014, o aumento de candidatos também foi maior para os cargos de Deputado Estadual/Distrital do que para Deputado Federal. Em 2010, as mulheres compunham 19,05\% do total de candidatos para Deputado Federal e 20,94\% para Deputado Estadual/Distrital; já em 2014 elas compuseram aproximadamente $29 \%$ do total de candidatos para ambos os cargos. 


\section{Gráfico 1: Candidatos por sexo para Câmara dos Deputados (Deputado Federal)}

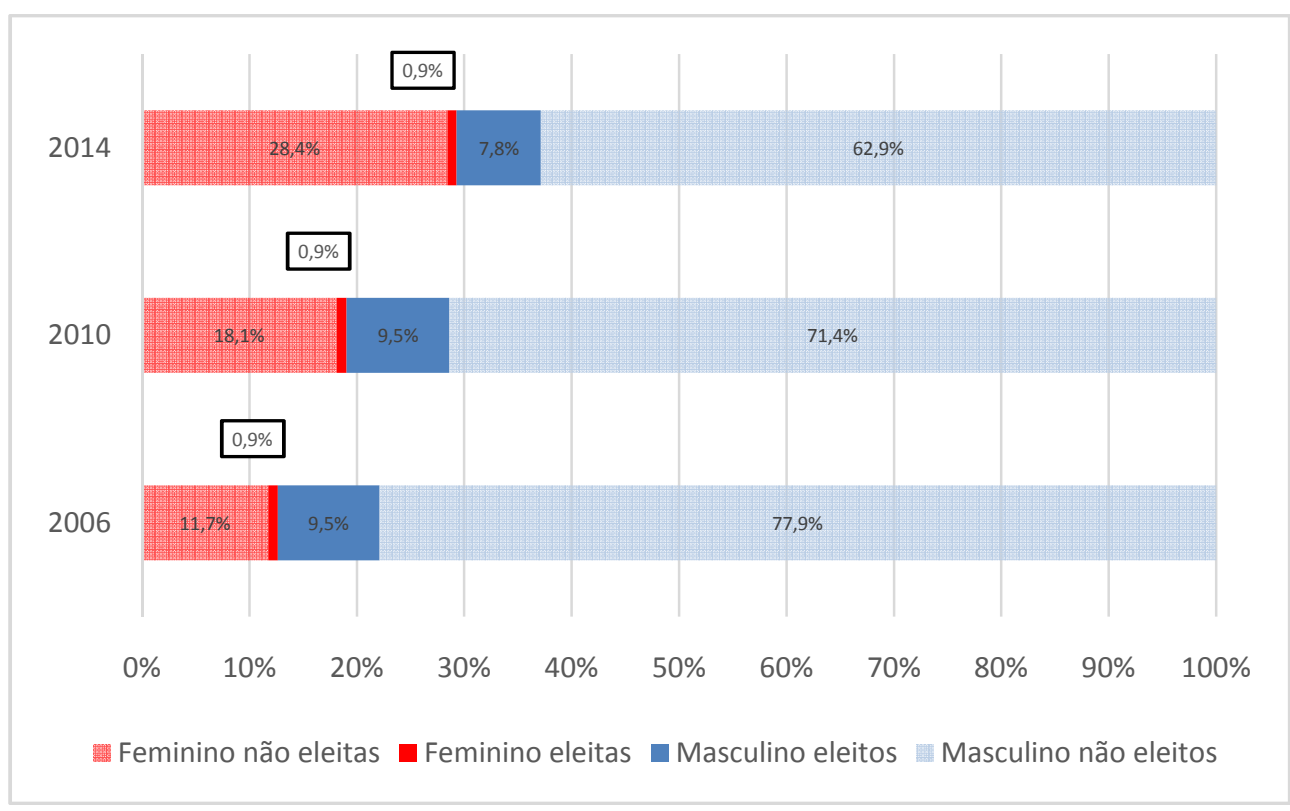

Fonte: Dados calculados pelos autores com base nas informações do TSE.

\section{Gráfico 2: Candidatos por sexo para Assembleias Legislativas (Deputado Estadual/Distrital)}

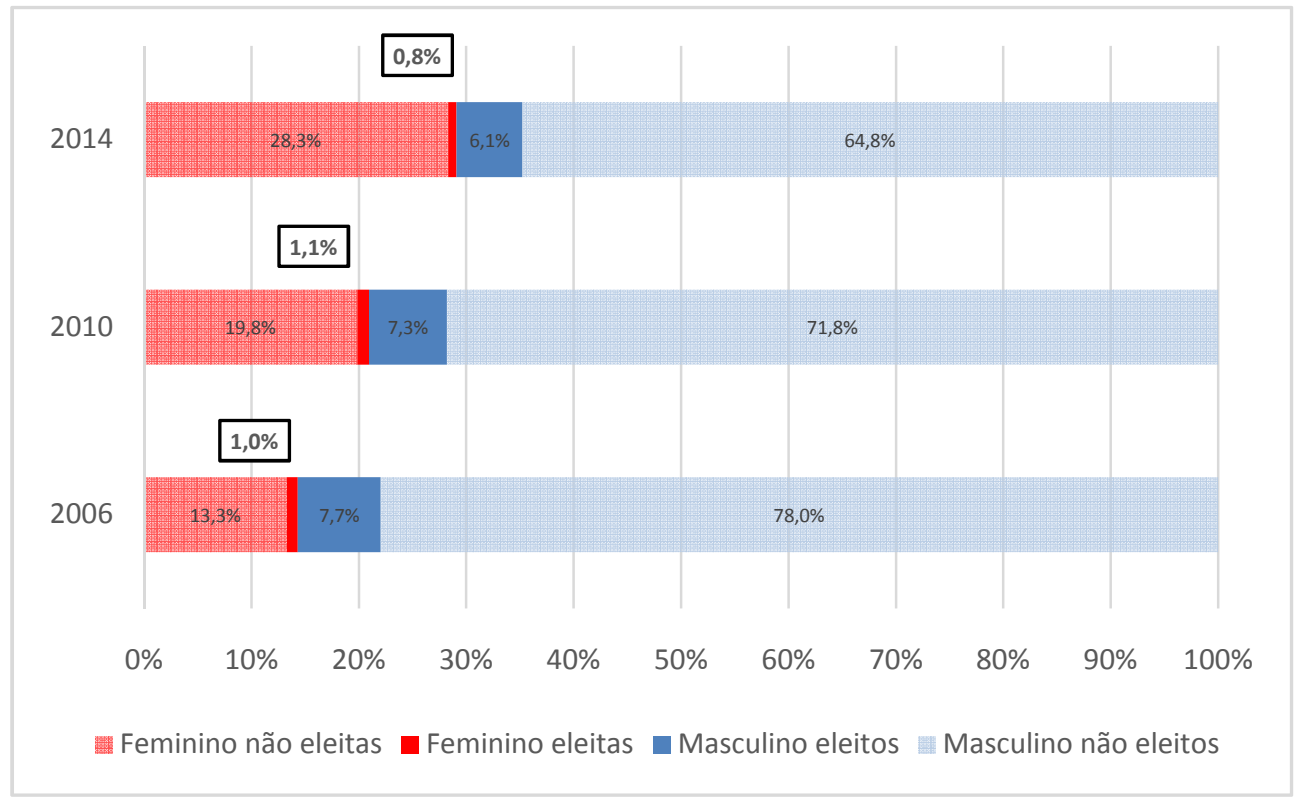

Fonte: Dados calculados pelos autores com base nas informações do TSE.

Como se observou acima, o aumento do número de candidatas não se refletiu no número de mulheres eleitas, que se manteve com poucas 
alterações e contribuiu para a queda da taxa de sucesso, como demonstra o Gráfico 3:

\section{Gráfico 3: Evolução das taxas de sucesso por sexo (2006 a 2014)}

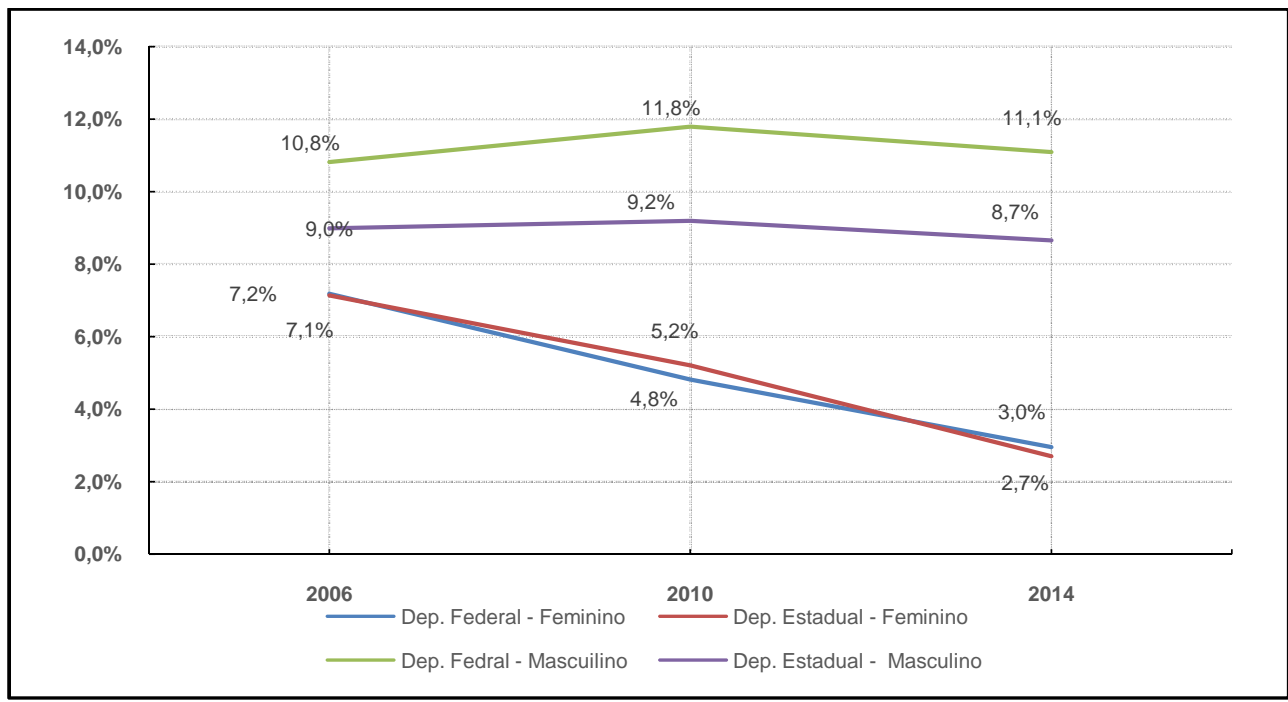

Fonte: Dados calculados pelos autores com base nas informações do TSE.

Em resumo, os resultados da política de cotas de gênero estabelecidas na lista partidária foram verificados apenas no quantitativo de oferta de candidatas, que aumentou $175 \%$ para a Câmara dos Deputados, e 156\% para as Assembleias Estaduais entre 2006 e 2014. Entretanto, nenhuma alteração substantiva ocorreu no número de mulheres eleitas. 0 que sinaliza para uma estratégia partidária de simplesmente inserir mulheres nas nominatas com a finalidade de evitar punições, mas sem oferecer às candidatas reais condições de competição.

\section{As eleições de 2014: portões e obstáculos à odisseia feminina}

Os dados comparativos das últimas três eleições (2006, 2010 e 2014) demonstraram um aumento significativo de candidaturas femininas, sem que isso tenha contribuído efetivamente para aumentar o número de mulheres na Câmara dos Deputados e nas Assembleias Legislativas Estaduais. Algumas questões sobre gênero, portanto, merecem mais atenção. Destarte, utilizar-se-á as eleições de 2014 para auxiliar a compreensão das estratégias partidárias e as possíveis consequências na estrutura de oportunidades para as mulheres candidatas. Algumas perguntas orientarão as análises, a saber: primeiro, qual o impacto da negação ao registro de candidaturas femininas? Quais as características sociodemográficas das mulheres que se candidatam? Por quais partidos competem? Mantidas 
constantes as demais características, o fato de ser mulher altera a capacidade de atrair votos e serem eleitas?

Em realidade, as questões acima se referem a tipos distintos de obstáculos à inserção das mulheres na política. Como analisou Pippa Norris $(1985,1997 a)$ até a chegada ao Parlamento, existem vários "portões" que necessitam ser ultrapassados e funcionam como espécies de filtros. A filiação partidária é o primeiro obstáculo formal a ser vencido pelas mulheres, posto que no Brasil apenas os indivíduos filiados aos partidos políticos podem se candidatar. Há poucos trabalhos sobre recrutamento e filiação partidária. Speck, Braga e Costa utilizaram dados do survey Estudos Eleitorais Brasileiro (ESEB) e demonstraram que apenas 3\% dos respondentes eram filiados a algum partido (SPECK; BRAGA; COSTA, 2015).

Em seguida, o segundo portão é representado pela composição das nominatas; decididas em convenções partidárias, as listas de candidatos são construídas seguindo estratégias próprias e é neste momento que incidem os efeitos das cotas para mulheres, que obrigam os partidos a lançar ao menos $30 \%$ de candidatas.

O terceiro portão é a Justiça Eleitoral, que pode contestar e barrar as candidaturas com base, por exemplo, na lei da Ficha Limpa. Nas eleições de 2014 os partidos apresentaram 2272 candidaturas femininas para a Câmara dos Deputados e 5666 para as Assembleias Estaduais. Entretanto, 17,9\% e 15,4\%, respectivamente, tiveram registros indeferidos pelos Tribunais Eleitorais, aproximadamente o dobro do percentual dos candidatos do sexo masculino em ambos os cargos. Isso significa dizer que as mulheres, além de estarem presentes em menor número nas listas partidárias, ainda sofrem um corte mais rigoroso do que os homens. Este fato necessita ser melhor investigado, mas à primeira vista parece ser mais uma evidência do pouco cuidado com os registros documentais pelos partidos do que um indício de discriminação nos tribunais. Ao tentarem a todo custo lançar candidaturas para cumprir a legislação das cotas os partidos podem ter realizado estratégias pouco criteriosas e o resultado foi 0 indeferimento de um grande número de candidaturas femininas. 
Cotas e mulheres nas eleições legislativas de 2014 - Vitor de Moraes Peixoto, Nelson Luis Motta Goulart e Gabriel Tisse da Silva

Tabela 2: Situação jurídica das candidaturas para Deputado Federal e Estadual (2014)

\begin{tabular}{|c|c|c|c|c|}
\hline CARGO & $\begin{array}{c}\text { SITUAÇÃO DA } \\
\text { CANDIDATURA }\end{array}$ & FEMININO & MASCULINO & TOTAL \\
\hline \multirow{8}{*}{ DEPUTADO FEDERAL } & CANCELADO & 0 & ,3\% & , 2\% \\
\hline & DEFERIDO & $75,7 \%$ & $84,9 \%$ & $82,0 \%$ \\
\hline & $\begin{array}{l}\text { DEFERIDO } \\
\text { RECURSO }\end{array}$ &, $1 \%$ &, $2 \%$ & ,2\% \\
\hline & FALECIDO & 0 & 1\% & , 0\% \\
\hline & INDEFERIDO & $17,9 \%$ & $9,4 \%$ & $12,1 \%$ \\
\hline & NÃO CONHECIDO & ,7\% & ,2\% & ,3\% \\
\hline & RENÚNCIA & $5,6 \%$ & $5,0 \%$ & $5,2 \%$ \\
\hline & TOTAL & $100,0 \%$ & $100,0 \%$ & $100,0 \%$ \\
\hline \multirow{8}{*}{$\begin{array}{c}\text { DEPUTADO } \\
\text { ESTADUAL/DISTRITAL }\end{array}$} & CANCELADO &, $0 \%$ & 1\% & 1\% \\
\hline & DEFERIDO & $78,3 \%$ & $87,2 \%$ & $84,4 \%$ \\
\hline & $\begin{array}{ll}\text { DEFERIDO } & \text { COM } \\
\text { RECURSO } & \end{array}$ & , 1\% & , 2\% & , 2\% \\
\hline & FALECIDO & 0 &, $0 \%$ &, $0 \%$ \\
\hline & INDEFERIDO & $15,4 \%$ & $7,5 \%$ & $10,0 \%$ \\
\hline & NÃO CONHECIDO & ,4\% & 1\% & , 2\% \\
\hline & RENÚNCIA & $5,7 \%$ & $4,8 \%$ & $5,1 \%$ \\
\hline & TOTAL & $100,0 \%$ & $100,0 \%$ & $100,0 \%$ \\
\hline
\end{tabular}

Fonte: Dados calculados pelos autores com base nas informações do TSE.

Busca-se, então, identificar se há algum padrão nas mulheres recrutadas e se existe diferenças entre os partidos. A questão que se coloca é: quais partidos são mais atrativos para cada sexo? Como se pode notar na tabela abaixo, deve-se comparar as taxas de atratividade entre os distintos partidos. Suponha que existem dois estoques de candidatos possíveis para serem disputados, um do sexo masculino e outro do sexo feminino. Os percentuais das colunas (a), (b), (c) e (d) se referem aos totais de homens e mulheres que se candidataram (percentual fecha $100 \%$ na coluna). Note-se que o fato de um partido 
lançar um elevado número de candidatas não significa necessariamente que o partido exerceu uma atração mais forte sobre as mulheres do que sobre os homens. Para que esta comparação seja realizada sem viés é necessário que se observe as taxas (divisões entre o percentual de mulheres e homens - $a / b$ e d/c): nos casos em que os indicadores se apresentarem maiores do que 1 , significa que o partido atraiu relativamente mais mulheres do que homens; quando os indicadores forem iguais a 1, significa que o partido atraiu homens e mulheres na mesma intensidade; e quando se observa indicadores menores do que 1, significa que o partido atraiu proporcionalmente com mais intensidade homens do que mulheres.

Para facilitar a comparação entre as duas distribuições (homem e mulher), as caselas com taxas dos partidos que concentraram mais mulheres do que homens foram coloridos de verde. Em 2014, os Partidos que foram mais atrativos para mulheres do que para os homens foram o PMDB, PSDB e PSB para Deputado Federal, e PSDB, PR e PPS para Deputado Estadual. Existem variações substanciais no que se refere aos partidos pelos quais as candidatas se lançam na disputa que apontam para usos de estratégias distintas.

Tabela 3: Taxa de atratividade dos partidos por sexo

\begin{tabular}{|c|c|c|c|c|c|c|}
\hline Partidos & $\begin{array}{l}\text { Deputad } \\
\text { Mulheres } \\
\text { (a) }\end{array}$ & $\begin{array}{l}\text { Federal } \\
\text { Homens } \\
\text { (b) }\end{array}$ & $\mathrm{a} / \mathrm{b}$ & \begin{tabular}{|} 
Depu \\
Estadual \\
Mulheres \\
(c)
\end{tabular} & $\begin{array}{l}\text { tado } \\
\text { 'Distrital } \\
\text { Homens } \\
\text { (d) }\end{array}$ & $c / d$ \\
\hline PT & 5,91 & 6,08 & 0,97 & 5,28 & 5,31 & 0,99 \\
\hline PMDB & 5,62 & 5,52 & 1,02 & 4,69 & 4,84 & 0,97 \\
\hline PSDB & 5,74 & 4,61 & 1,24 & 4,42 & 4,11 & 1,08 \\
\hline PP & 2,67 & 2,74 & 0,97 & 3,14 & 3,29 & 0,96 \\
\hline PSB & 6,26 & 5,98 & 1,05 & 4,87 & 5,10 & 0,96 \\
\hline DEM & 2,09 & 2,47 & 0,84 & 2,40 & 2,65 & 0,91 \\
\hline PDT & 4,46 & 4,88 & 0,92 & 3,93 & 4,03 & 0,98 \\
\hline $\mathrm{PR}$ & 2,78 & 3,03 & 0,92 & 3,66 & 3,21 & 1,14 \\
\hline PTB & 3,88 & 3,91 & 0,99 & 3,71 & 3,81 & 0,97 \\
\hline PPS & 1,86 & 2,02 & 0,92 & 2,99 & 2,82 & 1,06 \\
\hline Outros & 58,72 & 58,77 & 1,00 & 60,89 & 60,84 & 1,00 \\
\hline Total & 100,00 & 100,00 & 1,00 & 100,00 & 100,00 & 1,00 \\
\hline
\end{tabular}

Fonte: Dados calculados pelos autores com base nas informações do TSE.

Quarto portão é o recurso partidário. Uma vez que estão no páreo, os candidatos necessitam de apoio dos partidos para terem acesso, por exemplo, aos programas de rádio e TV. Como já apontado pela 
literatura que se dedica ao Horário Gratuito de Propaganda Eleitoral (HGPE), este é um recurso de uso discricionário dos partidos políticos, que utilizam estratégias que não privilegiam as mulheres na distribuição do tempo de rádio e TV, posto que é preferencialmente destinado a candidatos que tentam a reeleição ou que possuem influência nos governos e cúpulas partidárias. Estas estratégias tendem a reforçar a tendência na concentração de recursos em um determinado tipo de candidato, colaborando na influência da não renovação das bancadas partidárias. Mulheres e concorrentes que não ocupem cargos políticos tendem a ter suas presenças, na distribuição do HGPE, portanto, prejudicadas, o que faz com que as candidaturas não comecem o processo eleitoral em igualdade. Emerson Cervi (2011) realizou uma pesquisa envolvendo os 258 candidatos às 30 vagas paranaenses para a Câmara dos Deputados com intuito de verificar como os partidos distribuem o HGPE a seus candidatos, tendo como segundo objetivo analisar a hipótese segundo a qual as mulheres candidatas teriam menos espaços no HGPE que os homens. 0 autor constatou que as médias de tempo não são aleatórias, dado que os homens têm mais espaço do que as mulheres, discrepância que aumenta quando considerados os segmentos, que são limitados pela presença de um candidato ou orador diferente na tela da TV, ocupados por ambos os sexos.

0 aumento da sub-participação feminina no HGPE é, portanto, inerente às estratégias partidárias. Os partidos, contudo, atuaram de forma a distribuir o espaço no horário eleitoral favorecendo candidatos que tentam a reeleição ou que já fossem ocupantes de outros cargos eletivos (CERVI, 2011, p. 127). Os recursos utilizados em campanhas eleitorais pelas coordenações e pelas direções partidárias são utilizados de forma estratégica, como no caso do horário eleitoral. A distribuição de tempo, de maior para menor, privilegia os candidatos que tentam a reeleição, depois os que são ocupantes de cargos eletivos, posteriormente os cargos não eletivos e, por último, os candidatos sem mandatos. As mulheres, em paralelo com os homens, possuem presença predominante no grupo dos "sem mandatos". A questão de gênero, portanto, não é necessariamente responsável pelo tratamento destinado às mulheres, em relação ao HGPE, pelos partidos, mas sim as estratégias eleitorais que privilegiam candidatos que já tivessem sido eleitos.

O quinto portão a ser ultrapassado é o acesso aos recursos financeiros dos doadores. Como largamente discutido pela literatura, os gastos dos candidatos possuem impactos sobre a quantidade de votos, por conseguinte, na probabilidade de ser eleito (Cervi, 2012; Peixoto, 2010; Samuels, 2001). Portanto, o sucesso das candidaturas 
em boa medida está condicionado a ter aporte de recursos financeiros. 0 objetivo aqui é identificar qual o impacto dos gastos eleitorais, em geral, e das mulheres, especificamente, no total de votos. A hipótese central é que os retornos em votos para a mesma quantia de recursos financeiros dispendidos são maiores para as mulheres do que para os homens, dado que o dinheiro é a única forma das candidatas diminuírem as diferenças de recursos partidários monopolizados pelos homens como é o caso do HGPE.

Como se pode observar na Tabela 4, ficam nítidas as disparidades entre as despesas dos candidatos e das candidatas, em ambos os cargos nas eleições de 2014. Os homens tiveram em média valores mais elevados com suas despesas do que as mulheres. Para o cargo de Deputado Federal, a despesa dos candidatos foi em média $\mathrm{R} \$ 218,3$ mil a mais que o de mulheres, já para o cargo de Deputado Estadual essa diferença foi de $\mathrm{R} \$ 61,7 \mathrm{mil}$.

Tabela 4: Somatório Deflacionado das Despesas do Candidato nas Eleições de 2014

\begin{tabular}{clccccccc}
\hline \hline \multicolumn{1}{c}{ Cargo } & & N & $\begin{array}{c}\text { Média } \\
\text { (R\$ mil) }\end{array}$ & $\begin{array}{c}\text { Mediana } \\
\text { (R\$ mil) }\end{array}$ & $\begin{array}{c}\text { Desvio } \\
\text { Padrão } \\
\text { (R\$ mil) }\end{array}$ & $\begin{array}{c}\text { \% do } \\
\text { Total N } \\
\text { (R\$) }\end{array}$ & $\begin{array}{c}\text { \% do Total } \\
\text { Somatório } \\
\text { (R\$) }\end{array}$ & $\begin{array}{c}\text { Somatório } \\
\text { (R\$ } \\
\text { milhões) }\end{array}$ \\
\hline \multirow{2}{*}{ Dep Federal } & FEMININO & 1.376 & 84,9 & 4,8 & 391,4 & $27,7 \%$ & $9,7 \%$ & 116,8 \\
& MASCULINO & 3.590 & 303,2 & 19,2 & 735,5 & $72,3 \%$ & $90,3 \%$ & 1088,5 \\
& Total & 4.966 & 242,7 & 12,1 & 665,6 & $100,0 \%$ & $100,0 \%$ & 1205,3 \\
\hline \multirow{2}{*}{$\begin{array}{c}\text { Dep } \\
\text { Estadual/Distrital }\end{array}$} & FEMININO & 3.446 & 59,9 & 4,9 & 656,6 & $27,3 \%$ & $15,6 \%$ & 206,3 \\
& MASCULINO & 9.198 & 121,6 & 14,9 & 299,0 & $72,7 \%$ & $84,4 \%$ & $1.118,1$ \\
& Total & 12.644 & 104,7 & 10,6 & 428,1 & $100,0 \%$ & $100,0 \%$ & $1.324,4$ \\
\hline
\end{tabular}

Fonte: Dados calculados pelos autores com base nas informações do TSE.

* Os valores se restringem aos candidatos que prestaram contas ao TSE.

As diferenças entre os gastos ficam mais evidentes ao se observar o percentual dos candidatos e a relação desse valor com o percentual de despesas. Na disputa para o cargo de Deputado Federal, as mulheres compunham $27,7 \%$ do total de candidatos, cujas despesas foram de 116,8 milhões de reais, correspondentes a somente 9,7\% do somatório total das despesas; já os homens, que representam $72,3 \%$ dos candidatos, tiveram 1.088,5 milhões em despesas, o que correspondeu 
a 90,3\% do total de despesas. Em média, os homens dispenderam 3,57 vezes mais recursos em suas campanhas dos que as mulheres.

$\mathrm{Na}$ disputa para o cargo de Deputado Estadual, as mulheres compunham $27,3 \%$ do total de candidatos, cujas despesas foram de 206,3 milhões de reais, correspondentes a 15,6\% do somatório total das despesas, já os homens, $72,7 \%$ dos candidatos, tiveram 1.118,1 milhões em despesas, o que correspondeu a $84,4 \%$ do total de despesas. Em média, as candidaturas de homens dispenderam aproximadamente 2 vezes mais recursos dos que as candidaturas de mulheres.

No sexto portão estão os eleitores, que são os grandes juízes finais do processo eleitoral. Dificilmente se pode tirar conclusões sobre o preconceito e/ou discriminação na decisão do voto somente com análises dos resultados eleitorais. Todavia, as análises multivariadas sobre as razões de chances de se eleger um deputado ou deputada podem auxiliar na construção de teorias sobre as dificuldades de acesso a determinados bens.

Após um longo percurso em que candidatos ultrapassam os obstáculos de recrutamento, registro da candidatura, acesso aos recursos partidários e financiamento de campanhas, cabe perguntar como são as respostas dos eleitores. Ou seja, o que se pode afirmar quanto à tarefa de angariar votos? Há diferenças entre homens e mulheres nos diferentes cargos? Quais são as respectivas taxas de sucesso?

\section{Modelo logístico binário: probabilidade de ser eleito(a)}

Cabe ainda verificar se os resultados prejudiciais às mulheres permanecem, se mantidos constantes outros fatores. Se a causa do fenômeno - baixo desempenho eleitoral das mulheres - é mesmo explicada pelo fato de serem mulheres, ou se existem outros fatores como intervenientes. Para tanto, será inserida uma variável dummy ("ser mulher" = 1; "ser homem" = 0) no modelo econométrico que permitirá analisar exatamente $\mathrm{o}$ fator gênero num contexto multidimensional.

No intuito de obter os impactos separados das variáveis no nível individual foram construídos dois modelos econométricos para cada cargo, com o resultado da eleição como variável dependente (eleito = 1). Ou seja, o que se busca com este método é estimar o peso das condições individuais do(a)s candidato(a)s sobre as probabilidades de se eleger. 
No modelo 1, foram inseridas variáveis dummies para controlar os principais partidos; com exceção do PPS, todos foram significativos e positivos. A variável de grande impacto é a relativa aos que possuem mandato de deputado, ou seja, tentam a reeleição. A variável chave deste artigo é o sexo, atributo com significância e valor negativo, ou seja, ser mulher diminui em $69 \%$ as chances de se eleger para Deputada Federal e $67 \%$ as chances de se eleger para Deputada Estadual/Distrital.

O achado interessante é o desaparecimento do impacto da variável "sexo" ao ser introduzida a variável gastos de campanha no modelo 2. 0 mais intrigante é que esses resultados são mais acentuados no modelo para Deputado Federal do que para o cargo de Deputado Estadual/Distrital. Os efeitos negativos de ser mulher permanecem estatisticamente significativos para os Legislativos Estaduais, porém com impacto substantivo menor. A explicação para este fenômeno muito provavelmente está nos diferentes pesos que os recursos financeiros possuem para os cargos diferentes; enquanto para a Câmara dos Deputados é possível eliminar o efeito negativo de ser mulher no percentual de votos, estes efeitos permanecem para as Assembleias Estaduais.

Outro fato relevante a ser notado com a introdução da variável gasto é o efeito de ser Deputado, que diminui absurdamente, ainda que permaneçam com fortes impactos para ambos os cargos. A possível explicação para esse fenômeno é uma endogeneidade entre ter mandato e arrecadar recursos. Uma vez que se controlam os gastos eleitorais, o peso do mandato na possibilidade de se eleger diminui drasticamente. 
Tabela 5: Coeficientes dos modelos logit binário (Variável dependente: $\log$ do percentual de votos)

\begin{tabular}{|c|c|c|c|c|c|}
\hline \multirow{2}{*}{ CARGO } & \multirow{2}{*}{ VARIÁVES INDEPENDENTES } & \multicolumn{2}{|c|}{ MODELO 1} & \multicolumn{2}{|c|}{ MODEO 2} \\
\hline & & SIG. & $\operatorname{EXP}(B)$ & SIG. & $\operatorname{EXP}(B)$ \\
\hline \multirow[t]{10}{*}{ DEPUTADO FEDERAL } & MULHER & ,000 & 311 & 980 & 1,006 \\
\hline & PT & ,000 & 2,234 & 056 & 670 \\
\hline & PMDB &, 000 & 2,556 & 813 & ,947 \\
\hline & PFL - DEM & ,027 & 1,970 & 438 & 735 \\
\hline & PSDB & ,000 & 3,117 & , 186 & 1,443 \\
\hline & PPS & ,628 & 1,209 & ,268 &, 581 \\
\hline & DEPUTADO & ,000 & 36,854 & 000 & 3,846 \\
\hline & LOG. DESPESA DEFLACIONADA & - - & -- & 000 & 3,726 \\
\hline & CONSTANT & 0,000 & 052 & 000 & ,000 \\
\hline & MULHER & 000 &, 331 & 043 & ,762 \\
\hline \multirow[t]{8}{*}{ DEPUTADO ESTADUAL } & PT &, 000 & 1,956 &, 000 &, 528 \\
\hline & PMDB &, 000 & 2,639 & ,065 &, 761 \\
\hline & PFL- DEM & ,016 & 1,637 & ,979 & 1,007 \\
\hline & PSDB &, 000 & 2,249 & ,020 & ,662 \\
\hline & PPS & ,744 & ,921 & ,365 & ,756 \\
\hline & DEPUTADO & 0,000 & 42,993 & 000 & 6,702 \\
\hline & LOG. DESPESA DEFLACIONADA & -- & -- & 000 & 3,686 \\
\hline & CONSTANT & 0,000 & 047, & 000, & 000, \\
\hline
\end{tabular}

\section{Conclusão}

Após um longo processo de incorporação das mulheres na competição política é notável que as mesmas ainda se encontrem em situação desfavorável em comparação aos homens. As cotas de gênero não contribuíram com o aumento efetivo do número de mulheres eleitas, embora o tenham feito com o de candidatas. Quando se comparam os percentuais de mulheres nos parlamentos dos países democráticos, percebe-se que elas estão mais presentes nos sistemas proporcionais de lista com alta magnitude do que nos sistemas majoritários uninominais (Norris, 2004, 1985, 1997). 0 Brasil não foge à regra, as mulheres estão mais presentes nas disputas pelos cargos para as Assembléias Estaduais do que para a Câmara dos Deputados.

Uma explicação bastante razoável é que nas eleições para Deputado Federal a magnitude é menor, portanto, mais votos são necessários para se eleger, a competitividade é maior, por conseguinte, também maiores os custos de campanha.

A explicação para a baixa competitividade das mulheres nas eleições envolve os gastos das campanhas eleitorais, como foi 
observado por Peixoto (2010) nas eleições de 2006. Para as eleições de 2014, encontramos elementos que nos permitem afirmar que uma parte da explicação chave para a baixa competitividade das mulheres nas eleições envolve os gastos de campanha eleitorais. As candidatas gastam, em média, de 2 a 3,5 vezes menos do que os homens respectivamente para os cargos de Deputado Estadual/Distrital e Deputado Federal, fato que as deixa em posição de forte desvantagem nas disputas.

Embora haja fortes indícios de preconceito na seleção entre homens e mulheres por parte do eleitorado (e ainda anterior a este, na seleção dos próprios partidos), foi constatado um dispêndio de recursos extremamente desproporcional. Este fato, em grande medida, explica as modificações das significâncias tanto estatísticas quanto substantivas ocorridas na variável gênero ao se incluir a variável gastos de campanhas. Isso indica que parte considerável das diferenças de desempenho entre homens e mulheres é mitigada quando controlamos os gastos eleitorais.

\section{Referências}

ARAÚJO, C. As cotas por sexo para a competição legislativa: o caso brasileiro em comparação com experiências internacionais. Dados, v. 44, n. 1, 2001.

ARAÚJO, C. Feminismo e Poder Político, Uma Década depois. In: BIROLI, F.; MIGUEL, L. F. (Eds.). Teoria Política e Feminismo: Abordagens Brasileiras. 1. ed. Vinhedo: Novo Horizonte, 2012a.

ARAÚJO, C. Cidadania democrática e inserção política das mulheres. Revista Brasileira de Ciência Política, n. 9, p. 147-168, 2012b.

BIROLI, F.; MIGUEL, L. F. Introdução. In: BIROLI, F.; MIGUEL, L. F. (Eds.). Feminismo e Política. 1. ed. São Paulo: Boitempo, 2014.

CARVALHO, J. M. DE. Cidadania no Brasil: o longo caminho. [s.l.] Civilização Brasileira, 2001.

CERVI, E. U. O uso do HGPE como recurso partidário em eleições proporcionais no Brasil: um instrumento de análise de conteúdo. Opinião Pública, v. 17, n. 1, p. 106-136, 2011.

CERVI, E. U. Financiamento de campanhas e desempenho eleitoral no Brasil: análise das contribuições de pessoas físicas, jurídicas e partidos políticos às eleições de 2008 nas capitais de Estado. Revista Brasileira de Ciência Política, n. 4, p. 135-167, 2012.

KROOK, M. L. Reforming Representation: The Diffusion of Candidate Gender Quotas Worldwide. Politics \& Gender, n. 3, p. 303-327,2006.

MIGUEL, L. F.; QUEIROZ, C. M. Diferenças regionais e o êxito relativo de mulheres em eleições municipais no Brasil. Revista Estudos Feministas, v. 14, n. 2, p. 363-385, 2006. 
Cotas e mulheres nas eleições legislativas de 2014 - Vitor de Moraes Peixoto, Nelson Luis Motta Goulart e Gabriel Tisse da Silva

NICOLAU, J. M. História do Voto no Brasil. Rio de Janeiro: Jorge Zahar Editor Ltda, 2002.

NORRIS, P. Women's legislative participation in Western Europe. West European Politics, v. 8, n. 4, p. 90-101, 1985.

NORRIS, P. Passages to power: legislative recruitment in advanced democracies. Cambridge: Cambridge University Press, 1997.

NORRIS, P. Electoral engineering: voting rules and political behavior. Cambridge: Cambridge University Press, 2004.

NORRIS, P.; WELZEL, C.; INGLEHART, R. Gender Equality and Democracy. Comparative Sociology. [s.l: s.n.].

PEIXOTO, V. Eleições e Financiamento de Campanhas no Brasil. [s.l.] Instituto Universitário de Pesquisas do Rio de Janeiro, 2010.

PINTO, C. R. J. Feminismo, Historia e Poder. In: BIROLI, F.; MIGUEL, L. F. (Eds.). . Teoria Política e Feminismo: Abordagens Brasileiras. 1. ed. Vinhedo: Novo Horizonte, 2012. p. 290.

SAMUELS, D. Incumbents and challengers on a level playing field: Assessing the impact of campaign finance in Brazil. The Journal of Politics, v. 63, n. 02, p. 569-584, 2001.

SOARES, G. A democracia interrompida. Rio de Janeiro: FGV, 2001.

SPECK, B. W.; BRAGA, M. DO S. S.; COSTA, V. M. Estudo exploratório sobre filiação eidentificação partidária no Brasil. Revista de Sociologia e Política, v. 23, n. 56, p. 125-148, 2015.

Recebido em 01 de novembro de 2015

Aprovado em 05 de fevereiro de 2016

\title{
Quotas and women in Brazil's 2014 legislative elections
}

\begin{abstract}
This article explores the consequences of the institutional innovations introduced in the Brazilian electoral law with the positive discrimination policies, such as quotas for women on party lists. Describes the trajectory of the legislation after 1988 and analyzes the significant increase in women's participation in elections and the low electoral success for both the House of Representatives and the State Legislative Assemblies. It presents finally, an econometric model to measure the impact of the variable gender and other individual attributes of candidates in the 2014 elections.
\end{abstract}

Keywords: Legislative elections; representation; gender quotas; campaign finance. 